\title{
Short communication: Calcium partitioning during microfiltration of milk and its influence on rennet coagulation time
}

\author{
Justyna Zulewska, ${ }^{1}$ Jarosław Kowalik, Adriana Lobacz, and Bogdan Dec \\ Department of Dairy Science and Quality Management, Faculty of Food Sciences, University of Warmia and Mazury, 10-719 Olsztyn, Poland
}

\begin{abstract}
Pasteurized skim milk was subjected to (1) microfiltration $(\mathrm{MF})$ at $50^{\circ} \mathrm{C}$ and $(2) \mathrm{MF}$ at $6^{\circ} \mathrm{C}$ after storage at $2^{\circ} \mathrm{C}$. The products of these treatments were retentate (RMF50) and permeate (PMF50), and retentate (RMF6) and permeate (PMF6), respectively. Additionally, RMF50 was subjected to (3) cold MF after water dilution to produce retentate (RMF6R) and permeate (PMF6R). Calcium migration was monitored by analyzing ionic, soluble, and total calcium content in feed, retentates, and permeates. The influence of calcium partitioning and calcium addition to feed, retentates, and retentates diluted with water was determined. Without $\mathrm{CaCl}_{2}$ addition, only skim milk, RMF50, and RMF6 coagulated after rennet addition. Higher true protein and casein content of RMF50 and RMF6 resulted in shorter time of renneting. The retentates diluted with water showed no signs of coagulation within 40 min. The addition of PMF6R to RMF50 did not affect rennet coagulation time within the observed $40 \mathrm{~min}$ in comparison to RMF50 + water. In general, higher $\mathrm{CaCl}_{2}$ addition resulted in shorter rennet coagulation time. Special attention should be paid to calcium partitioning during membrane processing of cheesemilk. The level of calcium addition should be adopted to calcium content in such cheesemilk, which is affected by conditions of the filtration process (i.e., concentration factor and temperature).
\end{abstract}

Key words: calcium, rennet coagulation, membrane processing

\section{Short Communication}

Calcium is undoubtedly the key mineral constituent for cheesemaking. Following the first stage of rennet coagulation, the formation of the rennet coagulum is dependent on the availability of sufficient soluble cal-

Received March 26, 2018.

Accepted August 16, 2018.

${ }^{1}$ Corresponding author: justyna.zulewska@uwm.edu.pl cium, as well as adequate levels of colloidal calcium. Calcium ions influence coagulation by neutralizing negative charges on the casein micelles and probably forming linkages (salt bridges) between negatively charged phosphate groups on the casein micelles and promote their aggregation into a gel (McSweeney, 2007). The calcium ion activity of the milk influences the rennet coagulation time (RCT) and the firmness of the milk coagulum (Lucey and Fox, 1993). Variations in the level of calcium ions in cheese milk are usually compensated for by addition of calcium chloride, which accelerates rennet coagulation and reduces the $\mathrm{pH}$ of milk, facilitating the action of rennet. Because calcium in milk is mostly associated with casein micelles, fractionation of milk by microfiltration (MF) will result in calcium partition during membrane processing. Main application of MF in cheese making concerns removal of bacteria and spores from skim milk (i.e., Bactocatch system) and separation of micellar casein from serum proteins (SP). The average pore diameter of the membranes used during the process determines the application of MF. The aim of this study was to evaluate the level of calcium partition during different MF treatment (different temperature, different feeds) and its effect on rennet coagulation time as affected by calcium addition.

Bulk raw milk (about $30 \mathrm{~kg}$ ) was processed according to the protocol shown in Figure 1. Pasteurized $\left(72^{\circ} \mathrm{C}\right.$, 15 s) skim milk was split into 2 batches: one portion (approximately $3 \mathrm{~kg}$ ) was microfiltered at $50^{\circ} \mathrm{C}$ at 3.44 concentration factor $(3.44 \times)$ for protein fractionation (0.1 $\mu \mathrm{m}$ MF membranes), and the second (about 10 $\mathrm{kg})$ was kept at refrigerated conditions $\left(2^{\circ} \mathrm{C}\right.$, for at least $24 \mathrm{~h}$ ) to induce $\beta$-CN solubilization. The process of MF was carried out using benchtop crossflow pilot unit (Pall Membralox XLAB 5, Pall Corp., East Hills, NY). The system was equipped with $0.1 \mu \mathrm{m}$ nominal pore diameter ceramic membrane (ET1-070, a alumina, Pall Corp.). The retentate obtained during $\mathrm{MF}$ at $50^{\circ} \mathrm{C}$ (RMF50) after water dilution (it was diluted with reverse osmosis water back to a $1 \times$ concentration) was subjected to cold MF (an average temperature during processing was $6^{\circ} \mathrm{C}$ ). The second batch of milk after 


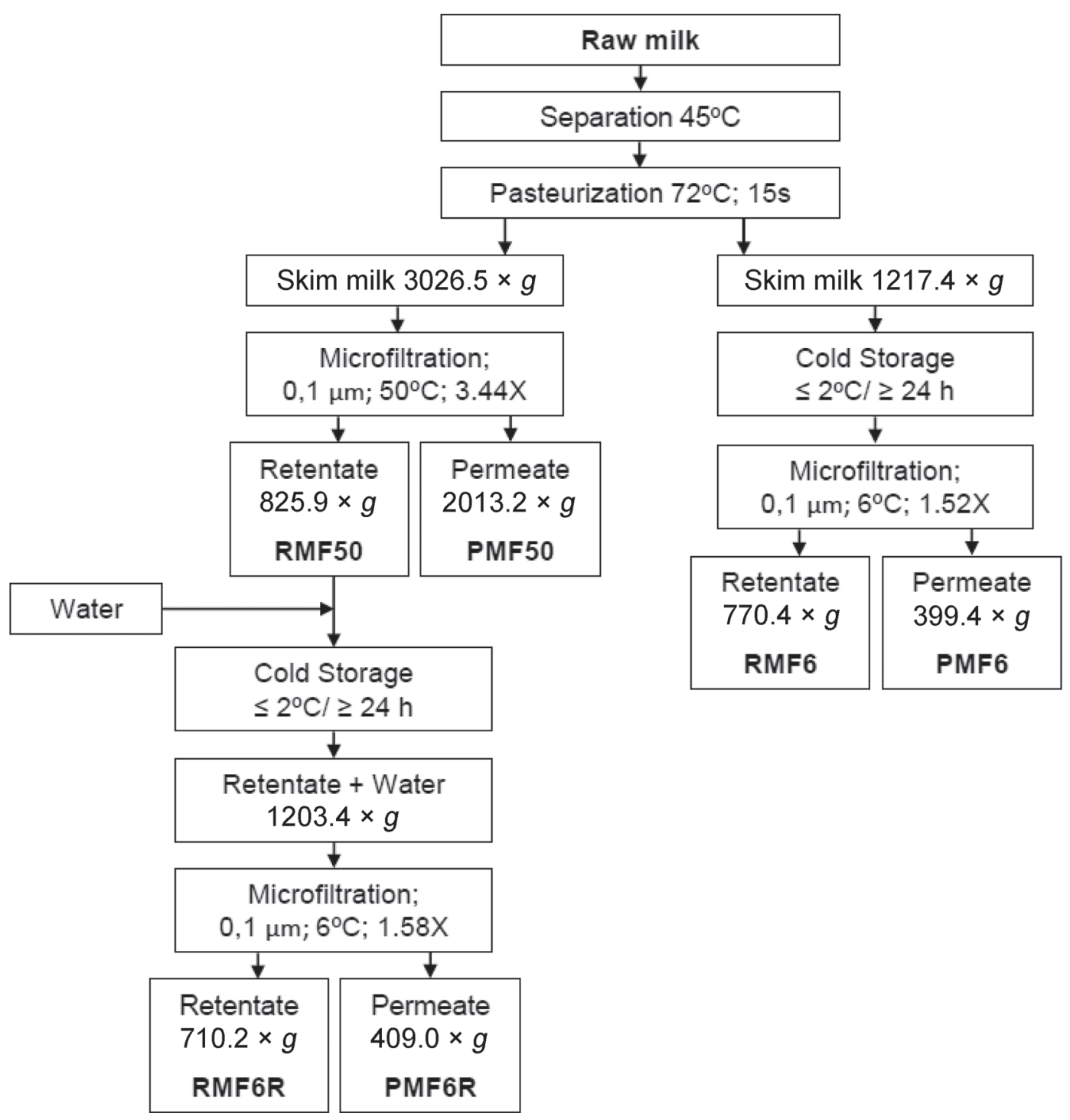

Figure 1. Experimental design of milk processing. Pasteurized skim milk was subjected to microfiltration $(\mathrm{MF})$ at 50 and $6^{\circ} \mathrm{C}$ after storage at $2^{\circ} \mathrm{C}$. The products of these treatments were retentate (RMF50) and permeate (PMF50), and retentate (RMF6) and permeate (PMF6), respectively. Additionally, RMF50 was subjected to cold MF after water dilution to produce retentate (RMF6R) and permeate (PMF6R).

storage at $2^{\circ} \mathrm{C}$ was cold microfiltered $\left(\right.$ at $\left.6^{\circ} \mathrm{C}\right)$ using the MF system described above. Cold MF of milk and milk with reduced SP content (RMF50 + water) was done to evaluate the influence of SP presence on $\beta-\mathrm{CN}$ passage through the membrane. The processing for each replicate was done over a 3 -d period. The experiment was replicated 3 times. The MF system operated only in batch mode.

To determine if significant differences were present in composition, calcium content, and rennet coagulation time depending on $\mathrm{CaCl}_{2}$ addition, the data were analyzed by ANOVA using Statistica (version 13.1, 1984-2016, StatSoft Inc., Tulsa, OK).
The samples of raw and pasteurized skim milk before processing, final retentates, and permeates were analyzed for TS, total nitrogen (TN), noncasein nitrogen (NCN), and NPN content using forced-air oven drying (AOAC International, 2007; method 990.20; 33.2.44), Kjeldahl (AOAC International, 2007; method 991.20; 33.2.11), Kjeldahl (AOAC International, 2007; method 998.05; 33.2.64) with modifications according to Wojciechowski and Barbano (2015), and Kjeldahl (AOAC International, 2007; method 991.21; 33.2.12), respectively. True protein was calculated by subtracting NPN from TN and then multiplying by 6.38 , casein was calculated by subtracting the NCN from TN and 
Table 1. Mean composition (\%) and $\mathrm{pH}$ of milk, retentates, and permeates produced

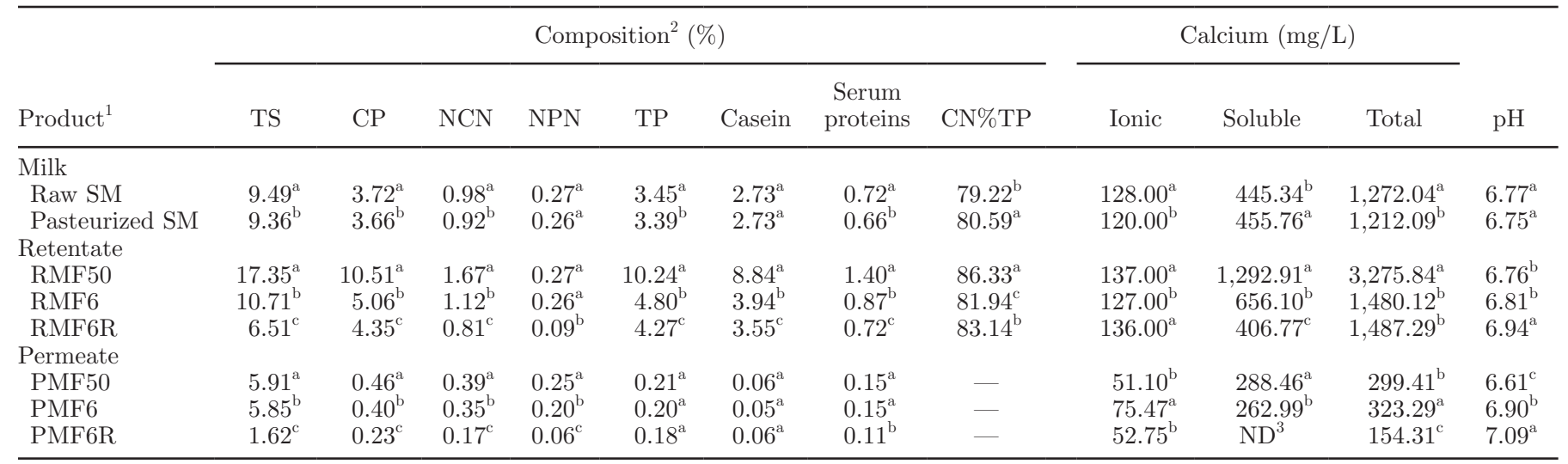

${ }^{a-c}$ Means in the same row within the specific group of products (milk, retentates, permeates) not sharing a common superscript are different $(P$ $<0.05)$.

${ }^{1} \mathrm{SM}=$ skim milk. Pasteurized skim milk was subjected to microfiltration (MF) at 50 and $6{ }^{\circ} \mathrm{C}$ after storage at $2^{\circ} \mathrm{C}$. The products of these treatments were retentate (RMF50) and permeate (PMF50), and retentate (RMF6) and permeate (PMF6), respectively. Additionally, RMF50 was subjected to cold MF after water dilution to produce retentate (RMF6R) and permeate (PMF6R).

${ }^{2} \mathrm{CP}=($ total $\mathrm{N} \times 6.38) ; \mathrm{NCN}=$ noncasein nitrogen $\times 6.38 ; \mathrm{NPN}=$ nonprotein nitrogen $\times 6.38 ; \mathrm{TP}=$ true protein $(\mathrm{CP}-\mathrm{NPN}) ;$ casein $=(\mathrm{CP}$ $-\mathrm{NCN}) ; \mathrm{CN} \% \mathrm{TP}=$ casein as percentage of true protein; serum proteins $=(\mathrm{TP}-$ casein $)$.

${ }^{3} \mathrm{ND}=$ not determined.

multiplying by 6.38 , and SP content was calculated by subtracting NPN from NCN and multiplying by 6.38 .

The ionic, soluble, and total calcium contents were analyzed in raw and pasteurized skim milk, the retentates (RMF50, RMF6, RMF6R), and the permeates (PMF50, PMF6, and PMF6R). The ionic calcium content was determined using IonMeter (model SevenMulti, Mettler Toledo, Greifensee, Switzerland) equipped with calcium ion selective electrode (perfectION, Mettler Toledo). The soluble and total forms of calcium were analyzed using atomic absorption spectrometry according to the method of IDF (2007) at the wavelength of $422.7 \mathrm{~nm}$. The soluble calcium was determined in ultrasupernatants produced by centrifugation of the samples at $47,808 \times g$ for $35 \mathrm{~min}$ at $37^{\circ} \mathrm{C}$ using Sorval RC6 plus centrifuge (Thermo Fisher Scientific, Waltham, MA) equipped with SS-34 rotor (Thermo Fisher Scientific).

All samples were analyzed fresh. However, the samples for soluble and total calcium analysis were stored at $-20^{\circ} \mathrm{C}$ before atomic absorption spectrometry analysis.

The rennet coagulation time (the time from rennet addition to first visible flocks) was determined for the following samples: pasteurized milk, RMF50, MF retentate 6 (RMF6), MF retentate $6 \mathrm{R}$ (RMF6R), RMF50 + PMF6R, RMF50 + water, RMF6 + water, RMF6R + water. The diluted rennet solution $(0.2 \mathrm{~mL}$ of rennet was added to $10 \mathrm{~mL}$ of water, then $0.15 \mathrm{~mL}$ of solution was added to $40 \mathrm{~mL}$ of milk or retentate) was added to skim milk and the retentates, and coagulation time was measured based on the visual observation by an experienced cheesemaker. Different levels of $\mathrm{CaCl}_{2}$
$(0.02,0.06,0.08$, and $0.1 \%)$ were added to the samples to investigate the influence of mineral composition on rennet coagulation. The retentates were diluted with demineralized water to bring them back to original volume based on the concentration factor $(\mathbf{C F})$. Additionally, the retentate with reduced SP content (RMF50) was diluted with PMF6R, which was added to improve the mineral balance of the mixture.

The compositions of the raw and pasteurized skim milk used in this study are shown in Table 1 . The casein as a percentage of true protein of the milk used in this study was typical of good quality raw milk.

Microfiltration at $50^{\circ} \mathrm{C}$ with $0.1-\mu \mathrm{m}$ membranes was carried out to reduce SP content in the retentate. The SP removal was only $14.69 \%$ and it was calculated according to Zulewska et al. (2009). Most of the nitrogen components were concentrated during the MF50 process (Table 1), which probably resulted from fouling of the membrane, which acted as an additional membrane layer. The fouling was measured based on flux decline. The average time of processing was $330 \mathrm{~min}$ and the average flux was $72 \mathrm{~kg} / \mathrm{m}^{2}$ per hour; however, the decline of $75 \%$ in flux was observed (the initial flux 114.11 vs. the end flux $28.89 \mathrm{~kg} / \mathrm{m}^{2}$ per hour).

Storage of milk at refrigerated conditions results in $\beta$-CN dissociation from the casein micelles. Thus, cold MF of milk has been used to produce $\beta$-CN enriched fractions (Terre et al., 1987; Woychik, 1992). Skim milk and RMF50 + water were subjected to cold MF. The RMF50 was diluted with demineralized water to bring it back to the original volume (calculated based 
on $\mathrm{CF}$ ); then, the mixture was stored at refrigerated conditions and subjected to cold MF. Cold MF of skim milk and RMF50 + water resulted in 7.52 and $6.32 \%$ $\mathrm{SP}$ removal, respectively. The processes were carried out at CF 1.52 and 1.58 for skim milk and RMF50 + water, respectively. The average flux during processing of skim milk was $13.31 \mathrm{~kg} / \mathrm{m}^{2}$ per hour as compared with $22.02 \mathrm{~kg} / \mathrm{m}^{2}$ per hour when processing RMF50 + water. Lower SP content along with water dilution also affected viscosity of the mixture and resulted in higher flux. Moreover, the flux decline during cold MF process of skim milk was $61.28 \%$ compared with $23.56 \%$ when processing RMF50 + water. During MF using membranes with pore size diameter of $0.1 \mu \mathrm{m}$, milk constituents of a size smaller than the pores of the membrane pass through it into the permeate fraction. This include SP, small micelles, and free $\beta-\mathrm{CN}$, which dissociated from the casein micelles at low temperature (Woychik, 1992). The results from SDS-PAGE electrophoresis (data not shown) confirmed the presence of $\beta-\mathrm{CN}$ fraction in the permeates: PMF6 and PMF6R. Interestingly, the casein present in RMF50 was both $\alpha-\mathrm{CN}$ and $\beta-\mathrm{CN}$. The change in the ratio of $\beta-\mathrm{CN}$ to $\alpha_{S^{-}} \mathrm{CN}\left(\beta-\mathrm{CN} / \alpha_{S^{-}} \mathrm{CN}\right)$ between thermized milk and retentate produced with $\mathrm{MF}$ at $6^{\circ} \mathrm{C}$ from that milk was determined in our previous experiment (Zulewska et al., 2018): 0.79 and 0.71, respectively. Any changes in the amount of $\alpha-\mathrm{CN}$ or $\beta$-CN would alter properties of milk and cheese. Altered protein profiles may also influence the development of flavor and texture as cheeses age; that is, during Cheddar cheese ripening, $\alpha_{\mathrm{S}_{1}-\mathrm{CN}}$ is completely hydrolyzed within 3 to $4 \mathrm{mo}$ and $\beta-\mathrm{CN}$ in cheese is very resistant to chymosin but is hydrolyzed slowly (approximately $50 \%$ at $6 \mathrm{mo}$ ) by plasmin (Fox and McSweeney, 1998; Sousa et al., 2001). However, application of the MF process to selectively fractionate $\beta$-CN brings several limitations.

Partitioning of the calcium between retentate and permeate during MF process depends on concentration factor used during the processing and the temperature (Table 1). Calcium in milk exists partly in soluble form and partly in an insoluble or colloidal form associated with casein (Fox and McSweeney, 1998). About twothirds of calcium is colloidal and connected with the casein micelles (Hui, 1993). Thus, the concentration of colloidal calcium is strongly correlated with the casein content of milk. During the MF process, calcium that is bond to casein micelle will be retained by the membrane unless the process is carried out at low temperature at which loosening of the micellar structure occurs. Under refrigerated conditions, $\beta$-CN dissociate from the casein micelles. Up to $50 \%$ of $\beta-\mathrm{CN}$, the most hydrophobic of the caseins, dissociates reversibly from the micelles on cooling, indicating the importance of hydrophobic in- teractions and suggesting that the micelle is sufficiently porous to allow the $\beta$-CN to diffuse out of the micelle (Fox and Brodkorb, 2008). These changes in casein micelles structure also affect calcium balance.

It might be assumed that at $3 \times \mathrm{MF}$ process carried out at $50^{\circ} \mathrm{C}$, the calcium bond to casein micelles remains in the retentate (that is, approximately two-thirds of total calcium in milk), and calcium present in serum phase (that is, approximately one-third of total calcium in milk) will be fractionated based on CF: 1 part will be retained by the membrane and 2 parts should pass through the membrane into the permeate. Taking the above considerations into account, for $3,026.5 \mathrm{~g}$ of the feed with $1,212.09 \mathrm{mg} / \mathrm{L}$ of calcium content, the calcium content in RMF50 should be approximately 2,800 mg. In the current experiment, the total calcium content of $3,275.84 \mathrm{mg} / \mathrm{L}$ for RMF50 corresponded to $2,705.52 \mathrm{mg}$ for $825.9 \mathrm{~g}$ of the retentate (Figure 1, Table 1). So, for the process of $\mathrm{MF}$ carried out at $50^{\circ} \mathrm{C}$, it is possible to calculate total calcium partition based on concentration factor, calcium concentration, and weights of the feed, retentate, and permeate. Interestingly, the total calcium content in PMF50 was significantly lower than calculated. That would suggest that the MF process at $50^{\circ} \mathrm{C}$ promotes precipitation of calcium phosphate as a result of prolonged temperature treatment.

When the MF process is carried out at refrigerated temperatures (below $10^{\circ} \mathrm{C}$ ), additional factors play a role in calcium migration between soluble and colloidal phase and thus through the membrane. The micelles are adversely affected by low temperature, at which the $\beta$-CN chains start to dissociate and the calcium hydroxyphosphate leaves the micelle structure, where it existed in colloidal form, and goes into solution (Bylund, 1995). The disintegration of $\beta-\mathrm{CN}$ at low temperatures results from weakening of the hydrophobic bonds (Atamer et al., 2017). Taking into account the weight and the calcium content in milk and CF of the process, the amount of calcium available for membrane passage was calculated. We did not obtain a good correlation between calculated and actual calcium. This might be caused by the fouling of the membrane. With the time of processing, the flux decline as a result of membrane fouling increased. Fouling phenomena is related to protein-membrane interactions. Generally, the proteins present in the feed solution subjected to the MF process can participate in one or more of the following membrane fouling phenomena: adsorption, deposition, and concentration polarization (Belfort et al., 1994). These interactions can cause pore constriction (narrowing), pore blockage (plugging), and gel/cake layer formation. When the diameter of a protein is much smaller than the diameter of a membrane pore, then the protein flows into the pore channel, deposits on the pore walls, and 
as a result, the pore radius becomes narrowed (Belfort et al., 1994). Proteins with a diameter similar to the diameter of the pores are responsible for pore blocking, whereas when the proteins are bigger than most pores, they form deposits or a cake on the upper surface of the membrane (Belfort et al., 1994). Some of these interactions may involve calcium; however, additional research is needed to confirm this assumption. Fox and Brodkorb (2008) reported that stability of the casein micelles decreases with the degree of concentration (i.e., concentration by evaporation or ultrafiltration), mainly due to the closer packing of casein micelles, an increase in $\left[\mathrm{Ca}^{2+}\right]$, and a decrease in $\mathrm{pH}$ due to the precipitation of $\mathrm{CaH}_{2} \mathrm{PO}_{4}$ and $\mathrm{CaHPO}_{4}$ as $\mathrm{Ca}_{3}\left(\mathrm{PO}_{4}\right)^{2}$ accompanied by the release of $\mathrm{H}^{+}$.

No difference was detected $(P>0.05)$ in total calcium content between RMF6 and RMF6R (Table 1). Both MF processes were carried out with almost the same CF (approximately 1.5 $\times$; Figure 1); however, the composition of the feed solution was different (the feed for RMF6 production was skim milk, whereas RMF6R was produced from RMF50 + water). Significant differences $(P<0.05)$ were detected for total calcium content for permeates (Table 1), with PMF6 having twice as much calcium than PMF6R. This might result from partial removal of calcium during the MF50 process. Most of the total calcium in the permeate was soluble calcium (Table 1). The ionic calcium content in the retentates was higher than in feed solutions and in permeates (Table 1). More advanced research is needed to show how the different treatments affect the calcium partition from various casein proteins during MF.

Mineral balance, especially calcium content of milk, is very important in the early stages of aggregation in rennet-induced gels. Without $\mathrm{CaCl}_{2}$ addition, only skim milk, RMF50, and RMF6 coagulated after rennet addition $(28.83,8.20$, and $12.67 \mathrm{~min}$, respectively; Table 2). Higher true protein and casein content of RMF50 and RMF6 resulted in shorter time of renneting. Interestingly, RMF6R did not show any signs of coagulation without $\mathrm{CaCl}_{2}$ addition within $40 \mathrm{~min}$, even though TP and calcium content was higher for RMF6R than for skim milk (Table 1). The rennet gelation behavior of milk gels is influenced by many variables including $\mathrm{pH}$ and the insoluble calcium content (Choi et al., 2007). As reported by Choi et al. (2007), the gelation time for rennet-induced milk gels increased with increased $\mathrm{pH}$. In current experiment, the $\mathrm{pH}$ of $\mathrm{RMF} 6 \mathrm{R}$ was higher than RMF50 and RMF6 (Table 1), which could affect the RCT.

The retentates diluted with water showed no signs of coagulation within 40 min. The addition of PMF6R to RMF50 did not affect RCT within observed 40 min in comparison to RMF50 + water. This was probably
Table 2. Effect of calcium chloride addition on rennet coagulation time (min) of milk and different microfiltration (MF) retentates produced

\begin{tabular}{lrrrrr}
\hline & \multicolumn{5}{c}{$\mathrm{CaCl}_{2}$ addition $(\%)$} \\
\cline { 2 - 6 } Product $^{1}$ & \multicolumn{1}{c}{0} & 0.02 & 0.06 & 0.08 & 0.1 \\
\hline Pasteurized SM & $28.83^{\mathrm{a}}$ & $16.00^{\mathrm{b}}$ & $14.50^{\mathrm{c}}$ & $11.00^{\mathrm{d}}$ & $10.00^{\mathrm{d}}$ \\
RMF50 & $8.20^{\mathrm{a}}$ & $7.83^{\mathrm{ab}}$ & $7.73^{\mathrm{b}}$ & $7.67^{\mathrm{b}}$ & $7.67^{\mathrm{b}}$ \\
RMF6 & $14.05^{\mathrm{a}}$ & $12.67^{\mathrm{b}}$ & $5.20^{\mathrm{c}}$ & $4.27^{\mathrm{d}}$ & $4.20^{\mathrm{d}}$ \\
RMF6R & $>40^{\mathrm{a} 2}$ & $6.53^{\mathrm{b}}$ & $3.82^{\mathrm{c}}$ & $3.13^{\mathrm{c}}$ & $3.05^{\mathrm{c}}$ \\
RMF50 + PMF6R & $>40^{\mathrm{a} 2}$ & $4.33^{\mathrm{b}}$ & $2.75^{\mathrm{c}}$ & $2.30^{\mathrm{c}}$ & $2.00^{\mathrm{c}}$ \\
RMF50 + water & $>40^{\mathrm{a} 2}$ & $35.28^{\mathrm{b}}$ & $14.73^{\mathrm{c}}$ & $13.13^{\mathrm{d}}$ & $12.22^{\mathrm{d}}$ \\
RMF6 + water & $>40^{\mathrm{a} 2}$ & $24.30^{\mathrm{b}}$ & $14.23^{\mathrm{c}}$ & $12.50^{\mathrm{d}}$ & $11.92^{\mathrm{d}}$ \\
RMF6R + water & $>40^{\mathrm{a} 2}$ & $26.20^{\mathrm{b}}$ & $18.32^{\mathrm{c}}$ & $13.30^{\mathrm{d}}$ & $9.22^{\mathrm{e}}$ \\
\hline
\end{tabular}

${ }^{\mathrm{a} e}$ Means in the same row not sharing a common superscript are different $(P<0.05)$.

${ }^{1} \mathrm{SM}=$ skim milk. Pasteurized skim milk was subjected to MF at 50 and $6^{\circ} \mathrm{C}$ after storage at $2^{\circ} \mathrm{C}$. The products of these treatments were retentate $(\mathrm{RMF} 50)$ and permeate $(\mathrm{PMF} 50)$, and retentate (RMF6) and permeate (PMF6), respectively. Additionally, RMF50 was subjected to cold MF after water dilution to produce retentate (RMF6R) and permeate (PMF6R).

${ }^{2}$ For statistical analysis, the value of 40 was used.

caused by the low calcium content of PMF6R (Table $1)$.

In general, higher $\mathrm{CaCl}_{2}$ addition resulted in shorter RCT. However, RMF50 did not show much differences in RCT (Table 2) as a function of calcium addition within the studied range ( 0 to $0.1 \%$ ). The addition of $0.1 \%$ of calcium chloride did not significantly reduce the coagulation time in comparison to $0.08 \% \mathrm{CaCl}_{2}$ addition for pasteurized milk, RMF6, RMF6R, RMF50 + PMF6R, RMF50 + water, and RMF6 + water (Table 2 ). For RMF50 the addition of more than $0.02 \%$ of $\mathrm{CaCl}_{2}$ was not justified. The addition of $\mathrm{CaCl}_{2}$ to RMF50 diluted with PMF6R resulted in the shortest time of coagulation (Table 2); however, no significant difference was detected $(P>0.05)$ between the sample with $0.06 \%$ of $\mathrm{CaCl}_{2}$ and higher $\mathrm{CaCl}_{2}$ supplementation (Table 2). The level of calcium addition should be adopted to calcium content in such cheesemilk, which is affected by conditions of the filtration process (i.e., concentration factor and temperature). The addition of calcium also affects the gel strength. Lucey and Fox (1993) reported that the addition of up to $10 \mathrm{mM}$ calcium increased gel strength, but higher concentrations of added calcium resulted in gel strength decrease.

\section{ACKNOWLEDGMENTS}

This work was supported by the Polish National Science Center, Kraków (grant number 2011/03/B/ NZ9/05159). The authors thank Władysław Chojnowski, Maria Czerniewicz, and Bogusław Staniewski for scientific advices during project realization. The technical assistance of Roman Łaszek, Waldemar Brandt, Magda 
Nowak, Maria Iglińska, and Justyna Ziajka (all working at the Department of Dairy Science and Quality Management, University of Warmia and Mazury in Olsztyn, Poland) was greatly appreciated.

\section{REFERENCES}

AOAC International. 2007. Official Methods of Analysis. 18th ed. AOAC International, Gaithersburg, MD.

Atamer, Z., A. E. Post, T. Schubert, A. Holder, R. M. Boom, and J. Hinrichs. 2017. Bovine $\beta$-casein: Isolation, properties and functionality. A review. Int. Dairy J. 66:115-125.

Belfort, G., R. H. Davis, and A. L. Zydney. 1994. The behavior of suspensions and macromolecular solutions in cross-flow microfiltration. J. Membr. Sci. 96:1-58.

Bylund, G. 1995. Dairy Processing Handbook. Tetra Pak Processing Systems AB, Lund, Sweden.

Choi, J., D. S. Horne, and J. A. Lucey. 2007. Effect of insoluble calcium concentration on rennet coagulation properties of milk. J. Dairy Sci. 90:2612-2623.

Fox, P. F., and A. Brodkorb. 2008. The casein micelle: Historical aspects, current concepts and significance. Int. Dairy J. 18:677-684.

Fox, P. F., and P. L. H. McSweeney. 1998. Dairy Chemistry and Biochemistry. Blackie Academic \& Professional, London, UK.

Hui, Y. H. 1993. Dairy Science and Technology Handbook. WileyVCH Inc., New York, NY.

IDF. 2007. 119:2007. Milk and milk products—Determination of calcium, sodium, potassium and magnesium contents. Atomic absorption spectrometric method. International Dairy Federation (IDF), Brussels, Belgium.
Lucey, J. A., and P. F. Fox. 1993. Importance of calcium and phosphate in cheese manufacture: A review. J. Dairy Sci. 76:1714-1724.

McSweeney, P. L. H. 2007. Cheese Problems Solved. Woodhead Publishing Ltd., Cambridge, UK.

Sousa, M. J., Y. Ardo, and P. L. H. McSweeney. 2001. Advances in the study of proteolysis during cheese ripening. Int. Dairy J. 11:327345

Terre, E., J.-L. Maubois, G. Brule, and A. Pierre. 1987. Method for producing a material enriched in beta casein, apparatus for implementing such process, and application of the products obtained by this process as foodstuffs, food supplements or additives in food and pharmaceutical industry or in the production of peptides physiological activity. Patent no. FR2,592,769. Inventor: E. Terre, J.-L. Maubois, G. Brule, and A. Pierre. Current assignee: Institut National de la Recherche Agronomique INRA, Sigma-Tau Industrie Farmaceutiche Riunite SpA.

Wojciechowski, K. L., and D. M. Barbano. 2015. Modification of the Kjeldahl noncasein nitrogen method to include bovine milk concentrates and mils from other species. J. Dairy Sci. 98:7510-7526.

Woychik, J. H. 1992. Preparation of simulated human milk protein by low temperature microfiltration. US Patent no. 5169666. Inventor: J. H. Woychik, Lafayette Hill, PA. Assignee: The United States of America as represented by the Secretary of Agriculture, Washington, DC.

Zulewska, J., J. Kowalik, and B. Dec. 2018. Flux and transmission of $\beta$-casein during cold microfiltration of skim milk subjected to different heat treatments. J. Dairy Sci. https://doi.org/10.3168/jds .2018-14496

Zulewska, J., M. W. Newbold, and D. M. Barbano. 2009. Efficiency of serum protein removal from skim milk with ceramic and polymeric membranes at $50^{\circ}$ C. J. Dairy Sci. 92:1361-1377. 